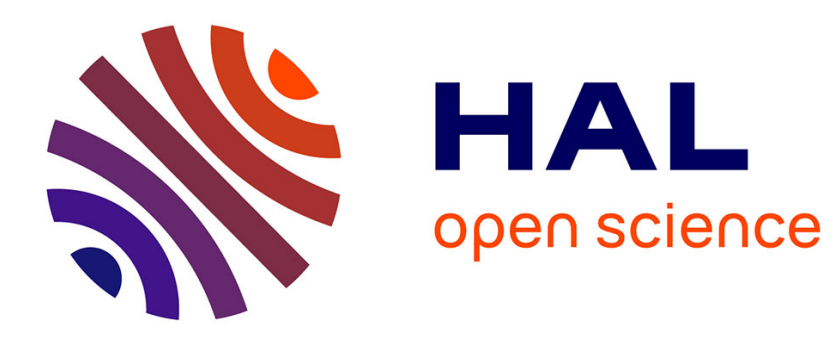

\title{
LATTICE IMAGES OF DISLOCATIONS IN GERMANIUM
}

\author{
A. Bourret, J. Desseaux
}

\section{To cite this version:}

A. Bourret, J. Desseaux. LATTICE IMAGES OF DISLOCATIONS IN GERMANIUM. Journal de Physique Colloques, 1979, 40 (C6), pp.C6-7-C6-9. 10.1051/jphyscol:1979602 • jpa-00219018

\section{HAL Id: jpa-00219018 https://hal.science/jpa-00219018}

Submitted on 1 Jan 1979

HAL is a multi-disciplinary open access archive for the deposit and dissemination of scientific research documents, whether they are published or not. The documents may come from teaching and research institutions in France or abroad, or from public or private research centers.
L'archive ouverte pluridisciplinaire HAL, est destinée au dépôt et à la diffusion de documents scientifiques de niveau recherche, publiés ou non, émanant des établissements d'enseignement et de recherche français ou étrangers, des laboratoires publics ou privés. 


\title{
LATTICE IMAGES OF DISLOCATIONS IN GERIMANIUM
}

\author{
A. Bourret and J. Desseaux
}

Centre d'études Nucléaires de Grenoble, Département de Recherche Fondomentale, Section de Physique du Solide 85 X, 38041 Grenoble Cedex, France.

\begin{abstract}
Résumé.- Des sous-joints de flexion pure dans le germanium ont été observês par microscopie electronique à haute résolution. Ces joints contiennent des dislocations coins non dissociēes et des dislocations dissociées en partielles. Une énergie de faute intrinsēque relativement élevée est dêduite si l'on suppose que les partielles ne tournent pas durant l'amincissement. Cependant aucune preuve expérimentale ne peut encore être fournie à I'appui de cette hypothèse.
\end{abstract}

Abstract.- Pure tilt subgrain boundaries in germanium have been studied by high resolution electron microscopy. They contain mainly undissociated edge dislocation and two types of split dislocations. A relatively high intrinsic stacking fault energy is deduced by supposing that no rotation of partials occurs during thinning. No experimental proof has yet been obtained to support this hypothesis.

1. Introduction. - Until recently it was supposed to be very difficult to interpret the lattice images of dislocations as obtained by electron microscopy. However a new development of this technique has begun due to a better understanding of imaging conditions and a good control of the defect geometry. The imaging mode (axial illumination) as applied down to a $3 \AA$ periodicity give an image directly related to the projected structure of the object in given conditions of thickness and of defocussing distance (this is specially true with high voltage instrument). For dislocations or any linear defect, an easy-to-read image is obtainable when the dislocation is stricly seen end-on. The smal1 angle grain boundary produced in a bicrystal is composed of dislocations whose Burgers vector and direction are easy to control. Germanium bicrystals with a [011] common axis have been by the Czochralski method in a graphite crucible under a pure argon atmosphere. The germanium has a $40 \Omega \mathrm{cm}$ resistivity and is p-type. Metallic impurities as measured by activation analysis are of the order of $10^{-2} \mathrm{ppm}$. The oxygen and carbon content has not yet been measured : techniques are being developed to measure these since the carbon whose segregation is important, may influence dislocation splitting.

This paper reports the results actualiy obtained about the structural aspects of dislocations in subgrain boundary, and stresses the problems which remain unsolved.

2. Dislocation structure in subgrain.- The subgrain boundary structure has shown a great complexity in the dislocation arrangement /1/ (Fig. 1) possibly due to splitting and stabilization of unuslial defects by mutual interaction in the grain boundary plane. Three main types of dislocations will be discussed here.

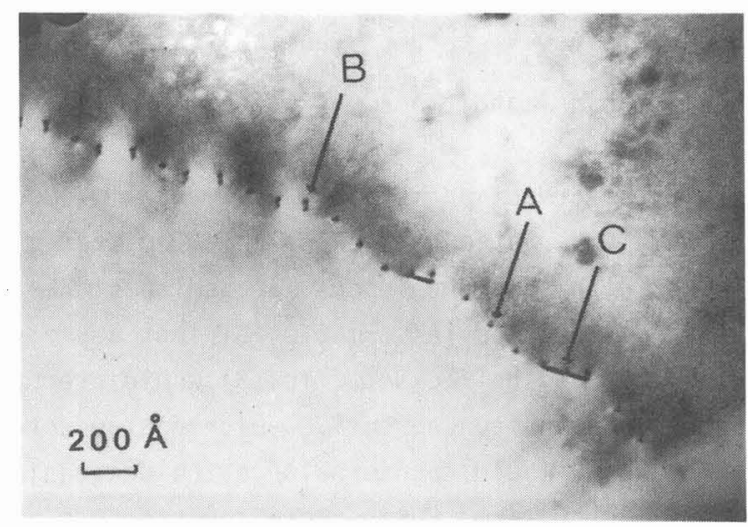

Fig. 1 : Part of a pure tilt [011] grain boundary in germanium (tilt angle : $2^{\circ} 5$ ) when viewed end-on along the $[011]$ common axis. Dislocation cores appear as black dots and stacking fault as straight segments joining cores. Three types of dislocation are recognizable : (A), non dissociated dislocation; (B), dislocation split into partials perpendicular to the grain boundary plane ; (C), three grouped dislocations seperated by stacking faults. Bright field multibeam imaging mode, $E=100 \mathrm{keV}$.

2.1. Pure edge dis location (Fig. 2_AL.- This dislocation has a Burgers vector $1 / 2[0 \overline{11}]$. It is Lomer dislocation as its direction contains two \{111\} planes. The glide plane is (100) and therefore this type of dislocation cannot be produced in the early stages of plastic deformation.

The high resolution image taken at $500 \mathrm{keV}$ shows clearly that no dissociation occurs ; furthermore a region of high contrast occurs in the dislocation core. Elasticity theory would predict a dissociated 
form with a sessible configuration for this dislocation. The expected reaction scheme is :

$$
\frac{1}{2}[0 \overline{1} 1] \rightarrow \frac{1}{6}[2 \overline{1} 1]+\frac{1}{6}[0 \overline{1} 1]+\frac{1}{6}[\overline{2} \overline{1} 1]
$$
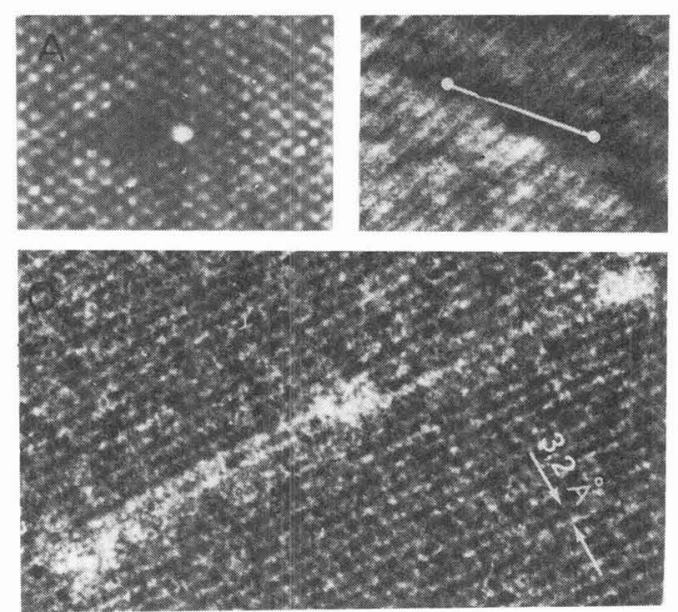

Fig. 2 : High resolution images of different type of defects in germanium : $(A)$, edge dislocation ; (B) $60^{\circ}$ dislocation split into two Shockley partials boarding an intrinsic fault ; (C), three identically grouped Frank dislocations separated by an intrinsic and an extrinsic stacking fault. (A) and (C) taken at $500 \mathrm{keV}$; (B) taken at $100 \mathrm{keV}$. Axial illumination, 5 beam imaging conditions including four (111) difraction spots.

In fact this reaction is not experimentally observed. From this observation it can be inferred that a shuffle set with no broken bonds $/ 2 /$ is the stable form of this dislocation. As a matter of fact any dissociation of the shuffle set (Fig. 3) would produce broken bonds and consequentiy a high energy core situation which would counterbalance the decreasing elastic energy term. Furthermore the presence of a seven ring and a five ring in this type of structure could produce a bright fot in the empty tunnel and a dark area in the compact region as observed experimentally : however this direct identification aithough already suggested by Krivanek /3/ must be checked by image matching. It is worth noting that similar non dissociated edge dislocations have been obtained in wurtzite structure /4/.

$$
\text { a }
$$

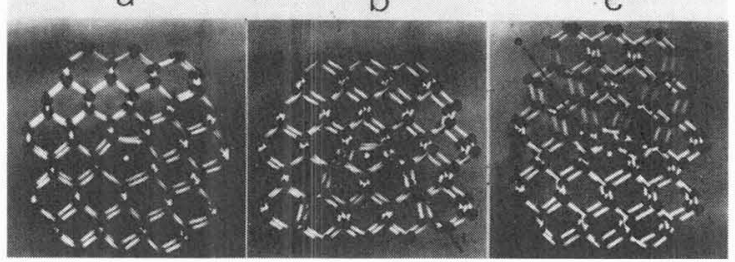

Fig. 3 : Different atomic models of the core of an edge dislocation along $[011]$. a) shuffle configuration, b) if dissociated with two intrinsic fauts, the number of open bonds is $2, c$ ) if dissociated with two extrinsic faults the number of open bonds is 6 . In fact only the configuration a) is observed
2.2. $60^{\circ}$ dis location_(Fig. 2 - B 2 .- Imaging this dislocation by two different $\{111\}$ atomic planes, one extra half plane is visible on only one set with a distinct stacking fault and no discontinuity on the other set. Thus the Burgers vector must be of the type $1 / 2<101>$ and these dislocations are of $60^{\circ}$ type. They are dissociated into two partials giving an edge Shockley dislocation and a $30^{\circ}$ Schockley dislocation. The two partials are visible even at medium range resolution when observed end-on with bright field multibeam condition (Fig. 4a). The stacking fault character is always intrinsic. This character is determined either from the high resolution image, the $30^{\circ}$ dislocation giving rise to a smooth discontinuity in contrast to the edge partial, or from weak beam images obtained after a large specimen tilt.


Fig. 4 : Testing the parallelism of $60^{\circ}$ dislocation in respect to the [011] direction.

a) Bright field multibeam imaging in a $800 \AA$ thick region : the two dark points indicate a very small rotation of the partials when viewed along the [011]direction.

b) Bright field multibeam imaging after a $3^{\circ}$ rotation of the specimen away from the [011] direction. The stacking fault is visible and is projected as a lozenge-shape (B) whose edges are slightly rotated in respect to the edge dislocation $(A)$. The rotation angle is now measurable and is approximately $\pm 1^{\circ}$

The splitting distance as deduced from atomic plane imaging gives an apparent distance of $31 \AA$ between partials. This gives an intrinsic stacking fault energy of $100 \mathrm{ergs} / \mathrm{cm}^{2}$. This relatively higher value than that obtained by weak beam $/ 5 /$ can be attributed to different impurity content or to the method of measurement itself (for discussion of the surface effect see below).

It has not yet been possible to distinguish the glide set and the shuffle set /6/ which might appear on the edge partial : however this may be possible if the partials remain stricly parallel to the [011] direction even in a thin foil. 
2.3. Group of Frank dis locations (Fig._2c).- One arrangement has been isolated on figure $2 \mathrm{c}$ : it includes three (111) atomic planes which stop at a Frank dislocation giving successively an intrinsic and an extrinsic stacking fault. The splitting occurs in the grain boundary plane contrary to the $60^{\circ}$ dislocation which splits perpendicular to the grain boun. dary plane. This dislocation arrangement is entirely edge in character and completely sessile : it accomodates misorientation between the two adjacent grains.

The splitting distance between Frank partials is not governed by the stacking fault energy angle of misorientation $\left(1-3^{\circ}\right)$, but rather by the distance between defects.

Another grouping not so frequently encountered, results from the following decomposition on two (111) planes :

$$
\frac{1}{2}[\overline{2} 1 \overline{1}]+\frac{1}{6}[\overline{2} 1 \overline{1}]+\frac{1}{3}[\overline{1} 1 \overline{1}]+\frac{1}{3}[\overline{1} 00]
$$

producing always an intrinsic fault cutting an extrinsic one at an acute angle.

These peculiar disiocation groupings are probably specific to tilt subgrain boundary and have never been observed in deformed material. However they give an opportunity to produce controlled intrinsic and extrinsic stacking faults.

3. Influence of the surface of the foil.- The observation of linear defects by high resolution microscopy is easy if the lines run stricly parallel to the observation direction. In order to fulfil this requirement the $\langle 011>$ direction seems to be the most appropriate as even during thinning the dislocations would have a tendancy to stay and 1 ie along throughs of the Peierls potential. However this assumption must be checked carefully. For the defect whose character is essentially sessile it is likely that no rotation during thinning would occur : such displacement would involve climbing which is excluded at room temperature. Therefore all the defects formed with Frank partials do not move. The same argument can be applied to the edge dislocation which cannot glide on the (001) plane. The question remains open for the $60^{\circ}$ dislocation only.

Smal 1 misalignement of the partials in respect to the [011] axis is very difficult to detect in a very thin region. (100 A). Actually our check is limited to $500-1000 \AA$ thick regions (Fig. 4) : in this range the rotation of $60^{\circ}$ dislocation is $1 \mathrm{imi-}$ ted to $\pm 1^{\circ}$ for dislocations $100 \AA$ apart from each other. Rotations seem to be alternately in one sense and in. the other as the screw components of the $60^{\circ}$ dislocations change sign. This misorientation would give a negligible effect in a $100 \AA$ thick region. However this small rotation could have been limited by the presence of other segments of dislocation along the grain boundary. A crude estimate of this effect using the Hazzledine approach with no friction force / $7 /$ shows that rotation is negligible if and only if the distance between the dislocations is smaller than half the thickness of the foil. Actua$11 y$ this condition is certainly not fulfilled for a very low angle grain boundary $\left(0.5^{\circ}\right)$ and small thickness where the splitting distance has been measured. Further experimental work is needed to clarify this point.

4. Conclusion.- The study of lattice defects in germanium by high resolution electron microscopy has been fruitful : Burgers vector, character of stacking fault, and analysis of complicated structures existing in small angle grain boundaries have been easily studied. However direct interpretation is actually limited to stricly end-on linear defect. This condition is verified for sessible configurations but has to be verified experimentally for glissile defects in thin foils : some efforts are necessary to find a practical way of doing this at a high resolution level.

\section{References.}

/1/ Bourret, A., Desseaux, J., Phi7. Mag. (to be pub] ished).

/2/ Hornstra, J., J. Phys. Chem. Solids 5 (1958) 129.

13/ Krivanek, 0.L., Isoda, S., Kobayashi, K., Phil. Mag. 36 (1977) 931.

14/ Mader, S., Blakeslee, A.E., IBM JAE 19 (1975) 151.

/5/ Gomez, A., Cockayne, D.J.H., Hirsch, P.B., "Vitek, V., PhiT. Mag. 31 (1975) 105.

16/ Hirth, J.P., Lothe, J., Theory of dislacations (MC Graw Hi11) 1968.

17/ Hazzledine, P.M., Karnthaler, H.P., Wintner, E., Phi1. Mag. 32 (1975) 81. 